\title{
DYNAMIC CHARACTERISTICS OF A PHO- TOCONDUCTING-ELECTROLUMINESCENT OPTOELECTRONIC SYSTEM WITH OPTICAL FEEDBACK
}

\author{
Z. PORADA ${ }^{\mathrm{a}, *}$ and E. SCHABOWSKA-OSIOWSKA ${ }^{\mathrm{b}}$ \\ 'Institute of Electrical Engineering, Technical University, Warszawska 24, \\ 31-155 Kraków (Poland); ' Department of Electronics, Academy of Mining and \\ Metallurgy, Al. Mickiewicza 30, 30-059 Kraków (Poland)
}

(Received 15 May 1996; In final form 17 June 1996)

\section{INTRODUCTION}

Thin film systems with photoconducting (PC) and electroluminescent (EL) elements can be divided into three groups. The first group comprises systems without feedback, the second, systems in which an optical feedback occures between the elements PC and EL, and the third, systems with unidirectional optical coupling occuring between the elements PC and EL. Each of these groups may found numerous applications ${ }^{1-3}$, but the most interesting are the PC-EL systems with optical feedback, as upon satisfying some conditions, these systems become bistable. A system composed of one PC element and two connected in parallel EL elements (Fig. 1), supplied with sinusoidal voltage, can be such a simple bistable system.

In such a system, the rectangular light pulses illuminating the PC element is the input signal and the light emitted from the element $\mathrm{EL}_{2}$ is the output signal. Owing to the occurrence of the optical feedback, the PC element is additionally illuminated with the light emitted by the $\mathrm{EL}_{I}$ element.

\footnotetext{
*Corresponding author.
} 


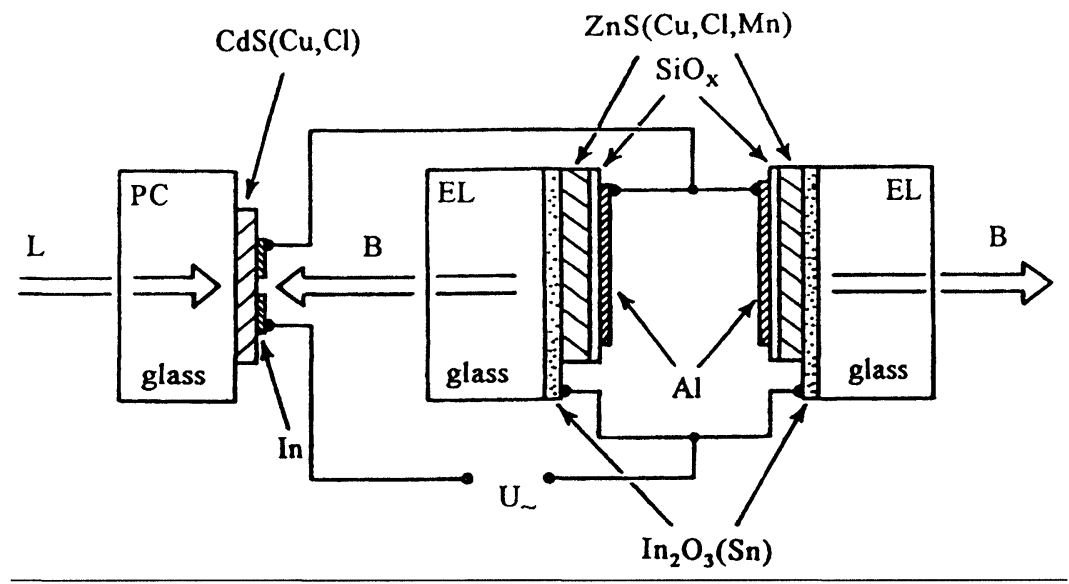

FIGURE 1 Arrangement of the thin film optoelectronic system with optical feedback

In the presented paper, the dependence of the output signal $B$ on the time for a bistable system was measured and the influence of supplying voltage and value of input signal on this dependence was determined.

\section{THEORETICAL CONSIDERATIONS}

A mathematical model describing the dynamic characteristics of the PC-EL system with optical feedback has been elaborated utilizing the arrangement presented in Fig. 1. In this model, the elements $\mathrm{EL}_{1}$ and $\mathrm{EL}_{2}$ have been assumed to have the same parameters, as they were prepared in the very same technological process.

PC-EL systems are supplied with an alternating sinusoidal voltage:

$$
U=U_{0} \sin (\omega t+\varphi)
$$

where $U_{O}$ is the amplitude, $\omega$ is the angular frequency, and $\varphi$ is the initial phase.

The instantaneous value of voltage $U_{E L}$ on the electroluminescent elements can be described by the equation: 


$$
\frac{d}{d t} U_{E L}=\frac{1}{2 C_{E L}}\left(U-U_{E L}\right)\left(G_{01}+G_{1}\right)
$$

where $C_{E L}$ is the capacitance of the EL element, $G_{O I}$ is the "dark" conductance of the photoconductive element PC, and $G_{I}$ is the instantaneous value of the conductance of PC element.

The instantaneous value of conductance $G_{l}$ can be expressed ${ }^{4,5}$ by the equation:

$$
\frac{d}{d t} G_{1}=a\left(L+\beta B_{1}\right)-\frac{G_{1}}{\tau},
$$

where $L$ is the instantaneous value of external illumination of the PC element (input signal), $B_{I}$ is the instantaneous value of the luminance of the EL, element, $\beta$ is the optical feedback coefficient of the PC element with the $\mathrm{EL}_{l}$ element, $a$ is a constant parameter for the given PC element, and $\tau$ is the photoconductivity rise time for this element.

The luminance $B\left(B_{1}=B_{2}=B\right.$, where $B_{2}$ is the luminance of the $\left.\mathrm{EL}_{2}\right)$ can be expressed by the formula given by Alfrey and Taylor ${ }^{6}$ :

$$
B=B_{0} \exp (-\gamma t) \exp \left(\frac{-b}{\sqrt{\left|U_{E L}\right|}}\right)
$$

where $B_{0}, \gamma$, and $b$ are constant parameters for given electroluminescent elements.

Solving the set of equations (1)-(4), one can calculate the dynamic characteristics of a system containing PC and EL elements.

\section{EXPERIMENTAL DETAILS AND RESULTS}

The PC devices (Figure 1) were prepared as gate-type systems on a glass substrate. The photoconductive layer was a $\mathrm{CdS}$ film ${ }^{7}$ doped with copper and chlorine and evaporated under vacuum at a pressure 0.007 Pa. Special purity undoped cadmium sulphide was used, evaporated from an alundum crucible heated by a tungsten wire resistor. The temperature of the source was in the range of $900^{\circ} \mathrm{C}$ to $950^{\circ} \mathrm{C}$. The distance of the substrate from the 
source was $12 \mathrm{~cm}$. During evaporation the temperature of the substrate was held constant at $150^{\circ} \mathrm{C}$. CdS films were simultaneously doped with $\mathrm{Cu}$ and $\mathrm{Cl}$, and recrystallized by heating the films whilst embedded in a $\mathrm{CdS}$ powder that had previously been doped with $\mathrm{Cu}$ and $\mathrm{Cl}$. The recrystallization was carried out at $550^{\circ} \mathrm{C}$ in air for $30 \mathrm{~min}$. The thickness of the $\mathrm{CdS}(\mathrm{Cu}, \mathrm{Cl})$ films was in the range of 6 to $14 \mu \mathrm{m}$. A metallic indium layer, deposited by vacuum evaporation, formed the upper electrode.

The electroluminescent device (Fig. 1) was a thin-film capacitor produced by the vacuum evaporation of copper-, chlorine-, and manganesedoped $\mathrm{ZnS}^{4,7}$. The evaporation was carried out under the pressure of 0.01 $\mathrm{Pa}$ from an alundum crucible heated to about $1100^{\circ} \mathrm{C}$ onto the substrate, which was placed $8 \mathrm{~cm}$ apart from the source and heated to $200^{\circ} \mathrm{C}$. The obtained $\mathrm{ZnS}(\mathrm{Cu}, \mathrm{Cl}, \mathrm{Mn})$ films were recrystallized by heating in a vacuum for $30 \mathrm{~min}$ at $300^{\circ} \mathrm{C}$. The thickness of the $\mathrm{ZnS}(\mathrm{Cu}, \mathrm{Cl}, \mathrm{Mn})$ films was in the range of 0.6 to $1.3 \mu \mathrm{m}$.

The lower transparent conducting electrode was tin-doped $\mathrm{In}_{2} \mathrm{O}_{3}$, obtained by the reactive cathode sputtering of $90 \% \mathrm{In}-10 \% \mathrm{Sn}$ alloy on a glass substrate, while the upper electrode was a vacuum-evaporated thin aluminium film.

A PC-EL system shown in Fig. 1 was supplied with a sinusoidal voltage. The input signal was in the shape of rectangular light pulses illuminating the photoconducting element, and the output signal was the luminance of the light emitted from the electroluminescent element. Part of the output signal was directed to the input, and thus, an optical feedback was produced in the system.

The theoretical analysis has shown that a PC-EL system with optical feedback may be a bi-stable system ${ }^{8}$ on condition that the feedback coefficient $\beta$ will have a value higher than $\beta_{L I M}$. As demonstrated in carried out investigations ${ }^{4,8}$, the limiting value $\beta_{L I M}$ depends on the amplitude and frequency of the voltage supplying the PC-EL system.

The results were compared with values computed using the above theoretical model. The experimental values of the parameters of the PC and EL elements were found to be as follows: $C_{E L}=3 \times 10^{-9} \mathrm{~F} ; \gamma=620 \mathrm{~s}^{-1}$; $b=17.1 \mathrm{~V}^{1 / 2} ; B_{O}=190 \mathrm{~cd} / \mathrm{m}^{2} ; \mathrm{G}_{O l}=7 \times 10^{-9} \Omega^{-1} ; \tau=0.6 \mathrm{~ms} ; a=$ $1.1 \times 10^{-3} \Omega^{-1} \mathrm{~lx}^{-1} \mathrm{~s}^{-1}$; and $\beta=0.6 \mathrm{~lx} . \mathrm{m}^{2} / \mathrm{cd}$.

In Fig. 2, the dependence of $B$ on the time for frequency $500 \mathrm{~Hz}$ and three values of supplying voltage amplitude $(280,420$, and $560 \mathrm{~V})$ are presented. 


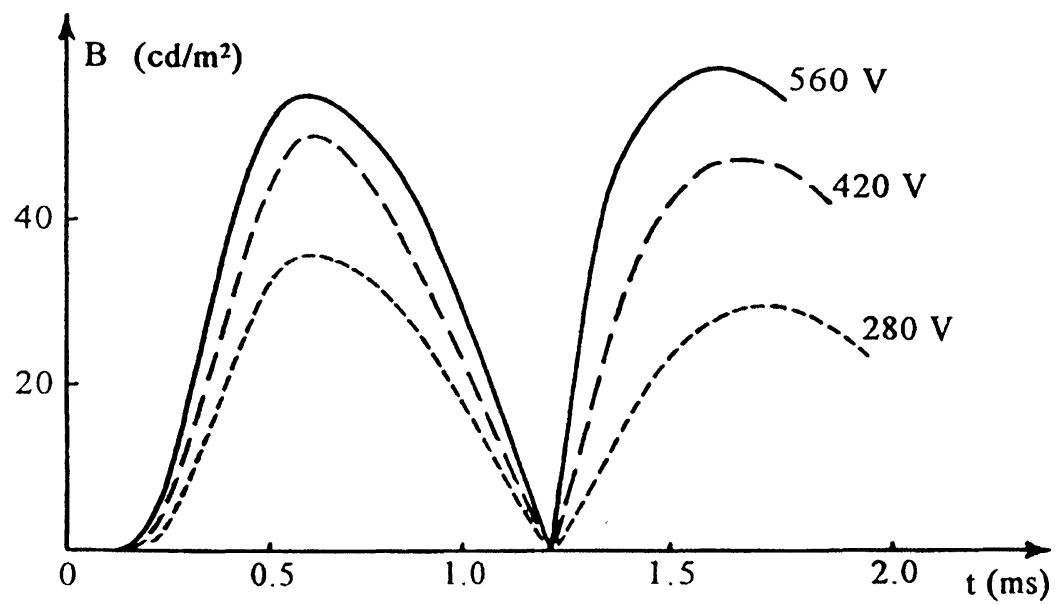

FIGURE 2 Dependences of luminance $B$ on time for frequency $500 \mathrm{~Hz}$ and $U_{o} 280,420$, and $560 \mathrm{~V}$

Fig. 3 shows the dependence of luminance $B$ on the time for applied voltage of amplitude $420 \mathrm{~V}$ at frequencies $100,200,500$, and $1000 \mathrm{~Hz}$, at illumination of the PC element with light pulse of $L=20 \mathrm{~lx}$ and duration $t_{0}=0.5 \mathrm{~ms}$.

In Fig. 4, the dependence on time of luminance $B$ for various values of input signal $L(1,2$ and $5 \mathrm{~lx})$ is shown at fixed parameters of supplying voltage $\left(U_{O}=420 \mathrm{~V}, f=500 \mathrm{~Hz}\right)$, and in Fig. 5, the dependence of amplitude of luminance $B$ on the duration $t_{0}$ of the light pulse, being the input signal (for $L=1 \mathrm{~lx}$ ), is given.

In Fig. 6 , the dependences of luminance $B$ on the time for various values of input signal $L$ by fixed duration of this signal $(\Delta t=0.5 \mathrm{~ms})$ and fixed parameters of supplying voltage $\left(U_{0}=420 \mathrm{~V}, f=500 \mathrm{~Hz}\right)$ are presented. As can be seen from this figure, at the input signal $0.21 \mathrm{x}$, the output signal $B$ vanishes with time. For $L=0.3 \mathrm{~lx}$, the second pulse $B$ has the same amplitude as the first pulse; it is then a boundary case $\left(L=L_{L I M}\right)$ for PC-EL system. For $L=0.5 \mathrm{~lx}\left(L>L_{\text {LIM }}\right)$, the second pulse of signal $B$. is higher than the first pulse. Thus, even at switched off $L$ signal, the system PC-EL will be in the ON state. 

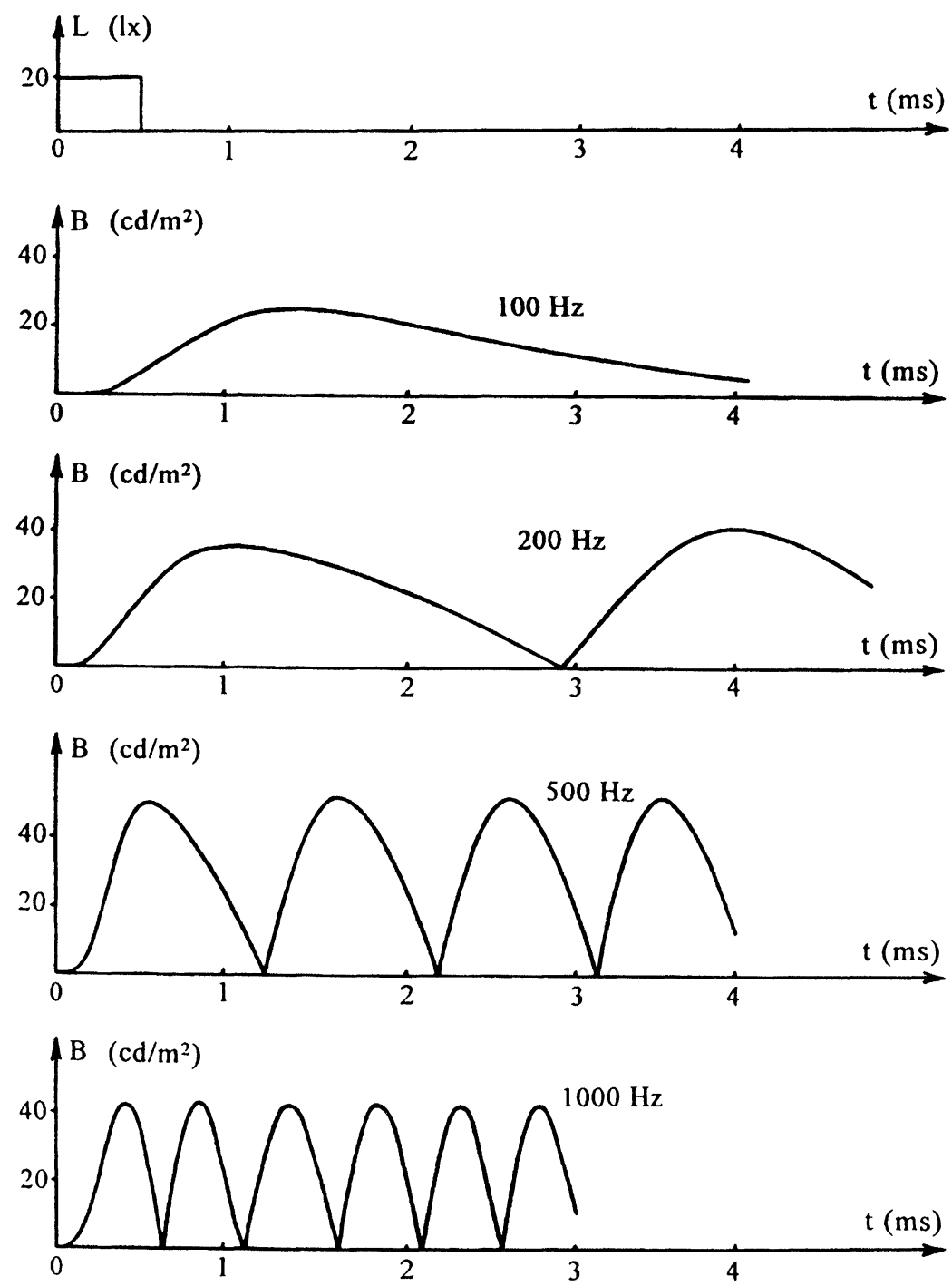

FIGURE 3 Dependences of luminance $B$ on time for $U_{o}=420 \mathrm{~V}$ and frequencies 100,200 , 500 and $1000 \mathrm{~Hz}$

The boundary value of input signal $L_{L I M}$ for various values of supplying voltage amplitude (frequency $500 \mathrm{~Hz}$ ) was also determined. As can be seen from the characteristic presented in Fig. 7, the boundary value of 

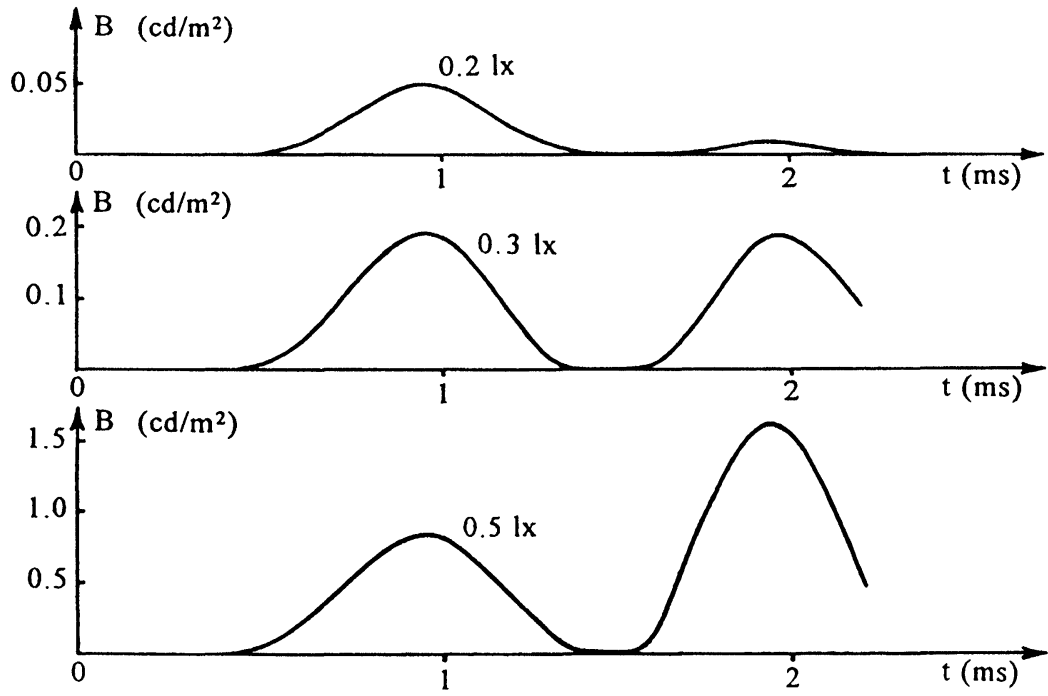

FIGURE 4 Dependence of luminance $B$ on time for various values of input signal $L(1,2$, $51 \mathrm{x})$ at $f=500 \mathrm{~Hz}, U_{o}=420 \mathrm{~V}, t_{o}=2 \mathrm{~ms}$

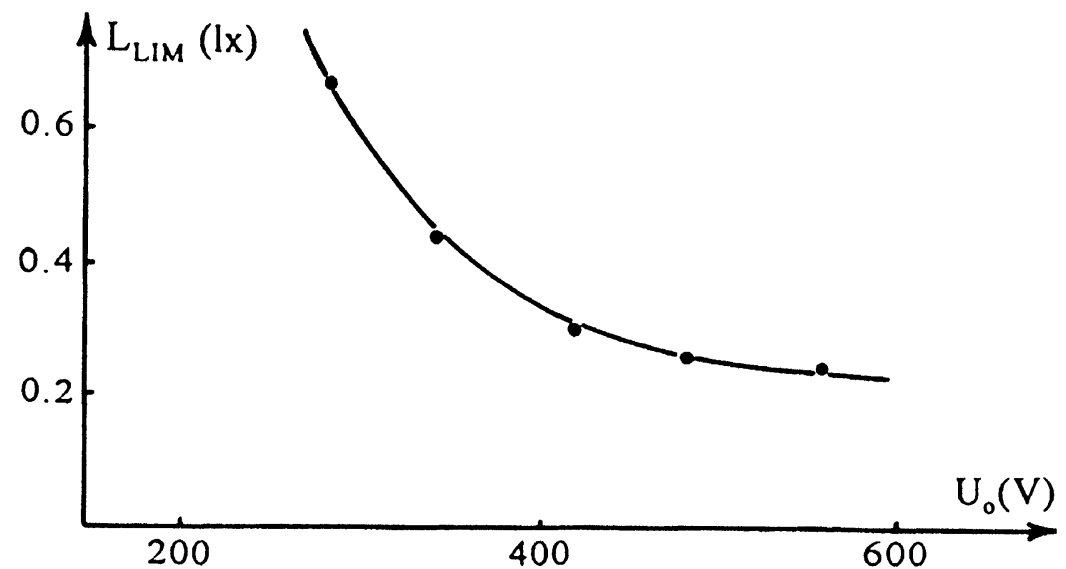

FIGURE 5 Dependence of amplitude $B_{O}$ of luminance on duration $t_{o}$ of input pulse at $L=11 \mathrm{x}$ 


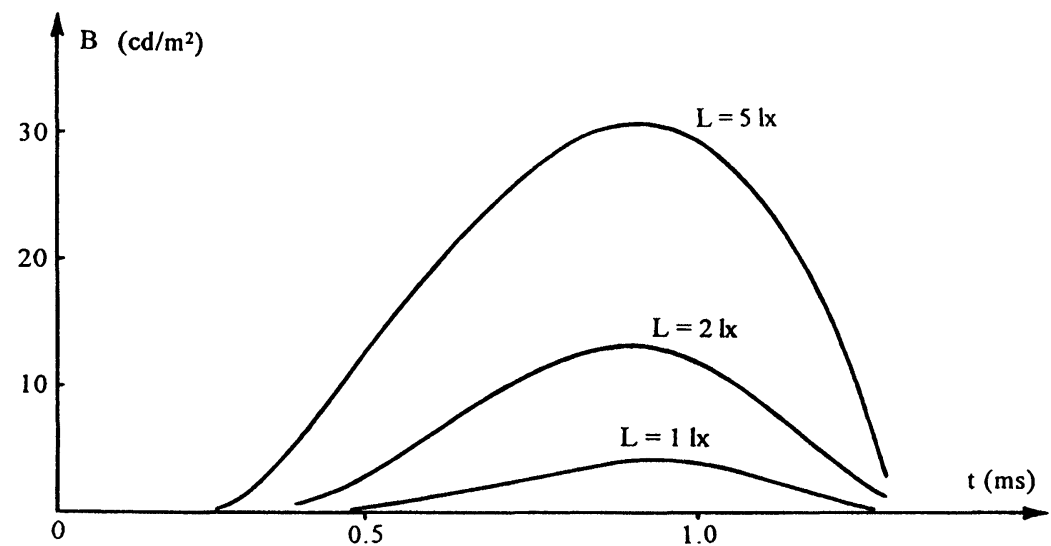

FIGURE 6 Dependence of the luminance $B$ on time for the PC-EL system for various values of input signal $L\left(L=0.21 \mathrm{x}<L_{L I M}, L=0.31 \mathrm{x}=L_{L I M}\right.$, and $\left.L=0.51 \mathrm{x}>L_{L I M}\right)$

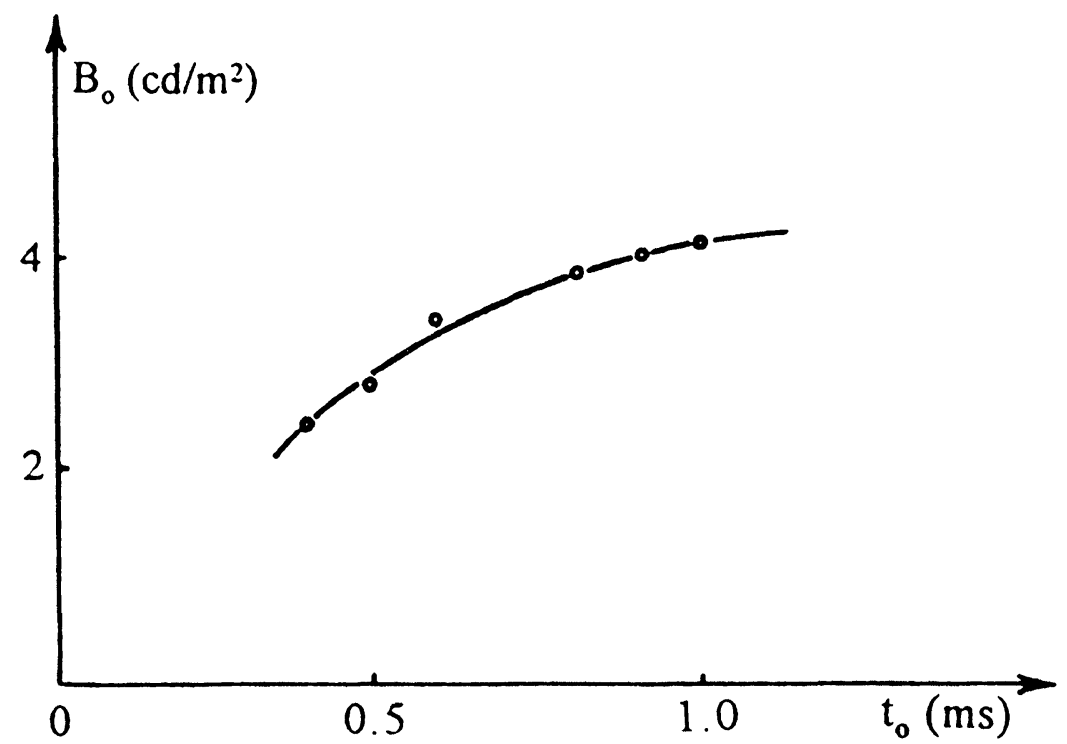

FIGURE 7 Dependence of boundary value of the input pulse height on the supplying voltage amplitude 
input pulse height $L_{L I M}$ decreases with the increase of the supplying voltage amplitude $U_{0}$.

\section{CONCLUSIONS}

Both the analysis of the proposed theoretical model and the measurements have shown, that for a photoconducting-electroluminescent optoelectronic system with optical feedback, the value of amplitude of luminance $B_{0}$ increases with the increase of the amplitude of the supplying voltage. The value of the luminance $B_{O}$ also changes with frequency of this voltage and achieves a maximum for the frequency of about $500 \mathrm{~Hz}$. The increase of the value of input signal $L$ also results in an increase of luminance $B_{0}$. Furthermore, the value of luminance $B_{O}$ increases with the lengthening of the duration $t_{0}$ of the light pulse being the input signal, but for the values of $t_{0}$ above $1 \mathrm{~ms}$, this increase is very low. Moreover, the boundary value of the input pulse height $L_{L I M}$ decreases with the increase of the supplying voltage amplitude $U_{0}$.

All the measurements discussed in the paper have been carried out for a bistable PC-EL system $\left(\beta>\beta_{L I M}\right)$. The characteristics obtained from the measurement showed a good conformity with the characteristics calculated on the base of the proposed theoretical model.

\section{References}

[1] Z. Szepesi, Thin Solid Films, vol. 13 (1972) 397.

[2] G. Olive, R.E.W. Lake, I.A. Bejar, Thin Solid Films, vol. 41 (1977) 151

[3] A.L. Bridges, AC thin-film electroluminescent TFEL display unit for cockpit control display unit application, SPIE Proceedings, vol. 1694 (1992).

[4] Z. Porada, Optoelectronic systems with thin film photoconducting and electroluminescent elements. Technical University of Cracow, Cracow 1994, Monography No 182 (in Polish)

[5] P.S. Kireev, Semiconductor Physics, Mir, Moscow 1979 (English translation).

[6] G.F. Alfrey, J.B. Taylor, Brit. J. Appl. Physics, vol. 4 (1955) 44S (supplement).

[7] Z. Porada, Thin Solid Films, vol. 125 (1985) 341

[8] Z. Porada, Thin Solid Films, vol. 109 (1983) 213. 

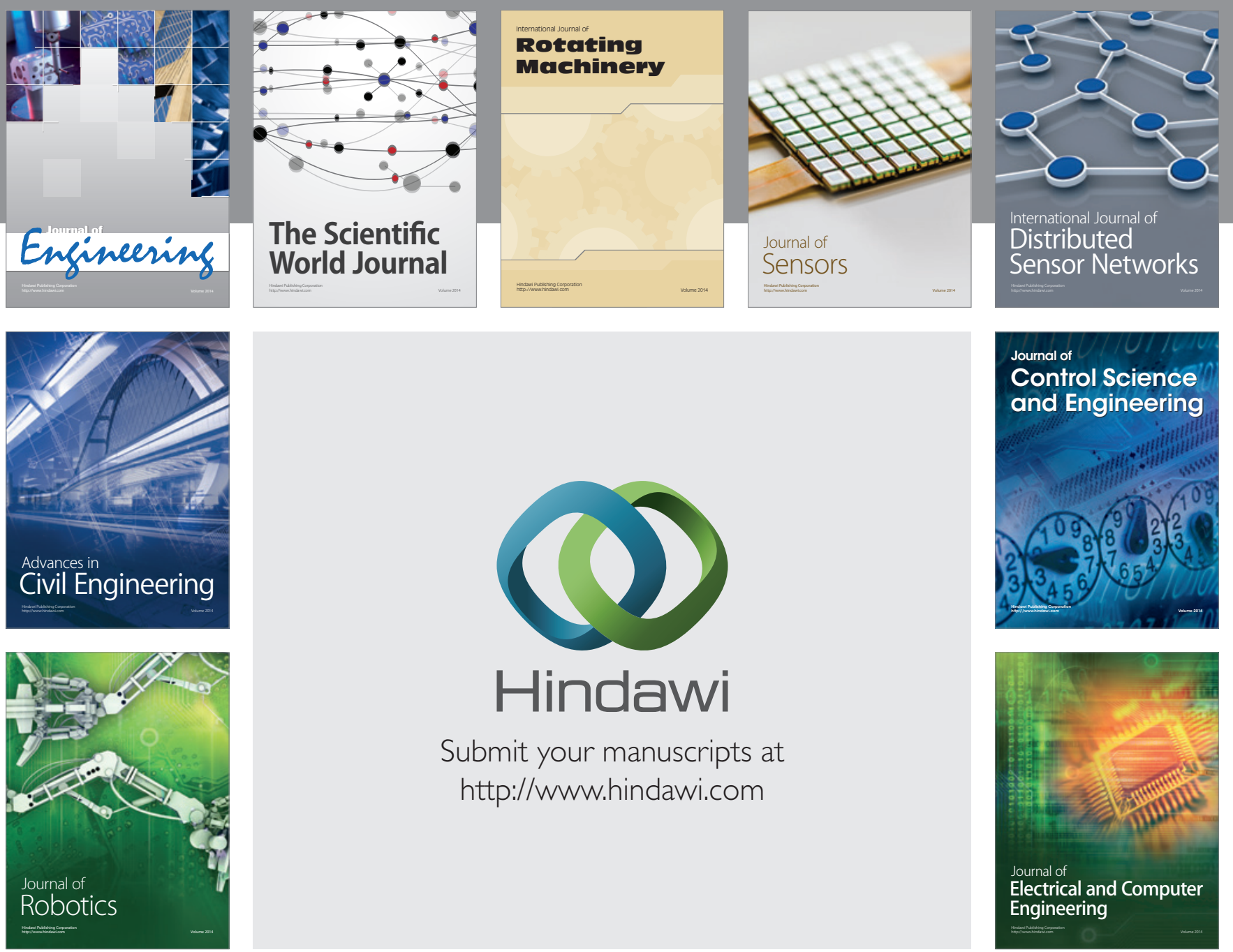

Submit your manuscripts at

http://www.hindawi.com
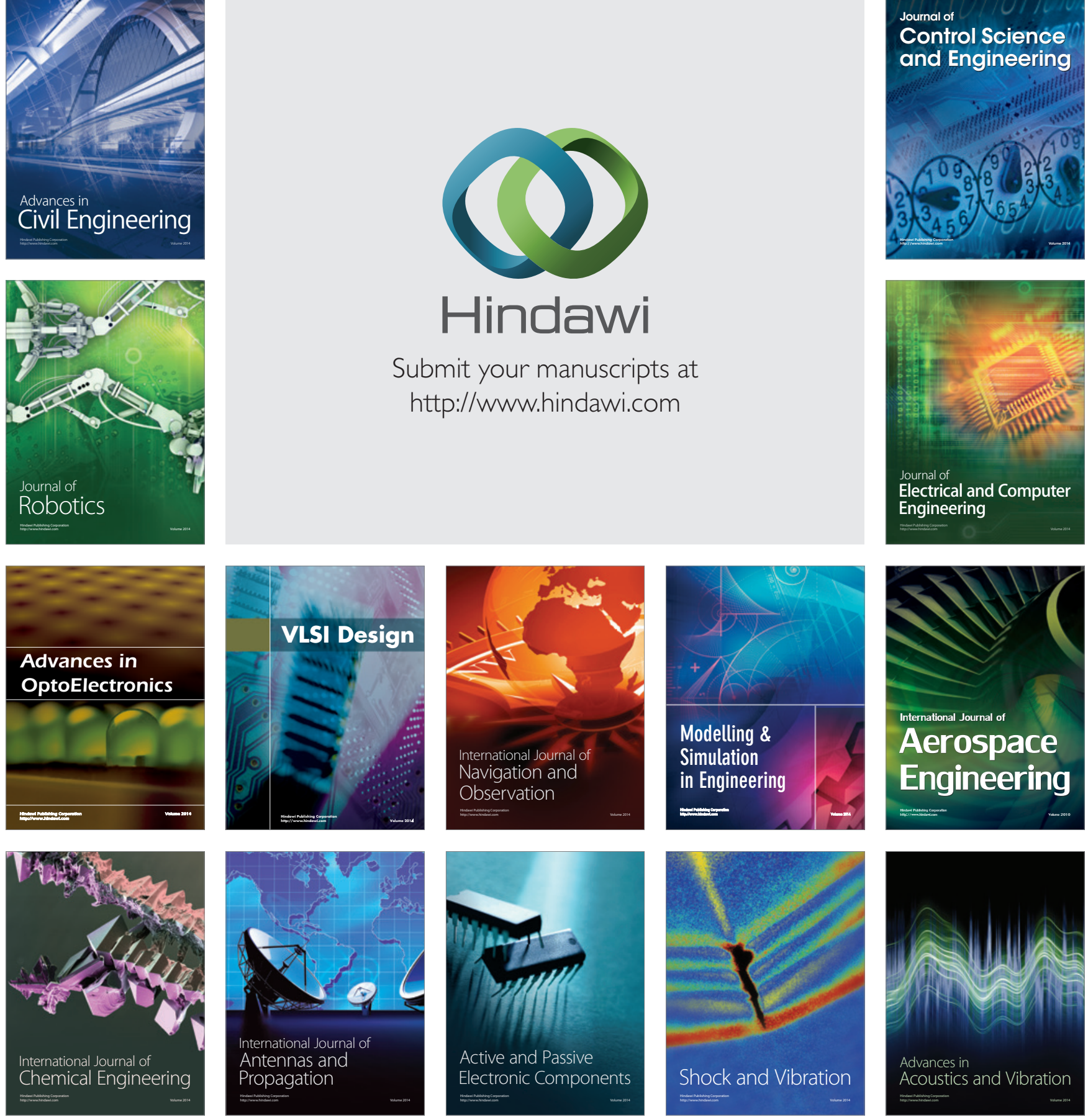